\title{
Valence Transition in Yb Hydrides*
}

\author{
Stefan Büchler, René Monnier and Leo Degiorgi \\ Laboratorium für Festkörperphysik, ETH Zürich, CH-8093 Zürich, Switzerland \\ Louis Schlapbach \\ Université de Fribourg, Pérolles, CH-1700 Fribourg, Switzerland
}

$\mathrm{Yb}$ exhibits an unstable $4 \mathrm{f}$ configuration in certain compounds. It has been shown experimentally and theoretically that $3 \mathrm{~d}$ core-level spectra of some rare earth ions exhibit satellite features which can be quantitatively related to the $4 \mathrm{f}$ occupancy in the ground state. We present $3 d$ photoelectron spectra of various $\mathrm{Yb}$-hydrides, measured with $\mathrm{Si} \mathrm{K} \alpha$ radiation at $1740 \mathrm{eV}$ photon energy. The results indicate divalent $\mathrm{Yb}$ in $\mathrm{YbH}_{1.8 \leq \mathrm{x} \leq 2}$ and mixed valency in the trihydrides $\left(\mathrm{YbH}_{2}<\mathrm{x} \leq 2.6\right)$.

\section{Introduction}

At moderate pressure and temperature $\mathrm{Yb}$ forms a solid solution phase with hydrogen, a nonmetallic dihydride phase $\left(\mathrm{YbH}_{1.8 \leq x \leq 2.0}\right)$ and a metallic trihydride phase $\left(\mathrm{YbH}_{\mathrm{x}}>2.50\right)$. The dihydride is orthorhombic and nonmagnetic, whereas the trihydride has been reported to be of fcc structure and magnetic /1/. Apparently the amount of hydrogen uptake is related to valence changes, which have not been studied previously.

Photoelectron spectroscopy has been shown to be a powerful tool for studying valence transitions in rare earth materials $/ 2,3,4,5,6,7 /$ including hydrides $/ 8,9,10,11 /$. Photoemission spectra of valence band and core levels of some rare earth ions ( $\mathrm{La}, \mathrm{Ce}$, $\mathrm{Sm}, \mathrm{Yb}, \mathrm{Lu}$ ) show features which can be understood in a many-electron picture only.

\footnotetext{
* Presented at the International Symposium on Metal-Hydrogen Systems, Fundamentals and Applications, Stuttgart, FRG, September 4-9, 1988.
} 
Model calculations /3,5,6/ based on the degenerate Anderson impurity hamiltonian describe spectroscopic data quite well. These models involve initial and final states of mixed $4 \mathrm{f}$ occupancy and as important interaction a hybridisation term between $4 \mathrm{f}$ and valence states. In the case of $\mathrm{Yb}$ the groundstate $\mathrm{Ig}>$ is the superposition of two states with 13 and 14 ff electrons, respectively:

$$
\left|g>=\alpha g 14 f^{13} 3 d^{10} v^{3} l^{3}\right\rangle+\beta g\left|4 f^{14} 3 d^{10} v^{2} l^{2}\right\rangle
$$

The first term corresponds to trivalent, the second to divalent Yb. Similarly, the final state $|\mathrm{f}\rangle$ of the $3 \mathrm{~d}$ photoemission process is written as :

$$
\left.|f\rangle=\alpha_{f}\left|4 f^{13} 3 d^{9} v a l^{3}\right\rangle+\beta_{f}\left|4 f^{14} 3 d^{9} v^{2}\right|^{2}\right\rangle
$$

For the sake of brevity we use the obvious abbreviations $4 \mathrm{f}^{13}$ and $4 \mathrm{f}^{14}$, respectively, for the two contributions to the final and the ground state.

A localized $4 \mathrm{f}$ electron screens a $3 \mathrm{~d}$ hole much better than a continuum state. In the photoemission process the outgoing electron is much stronger coupled to a poorly screened ion than to one with a full $4 \mathrm{f}$ orbital. Therefore the kinetic energy of the former is lower and in the $3 \mathrm{~d}$ photoemission experiment the $4 \mathrm{f}^{13}$ final state appears to be more strongly bound than the $4 \mathrm{f}^{14}$. In the case of the $\mathrm{Yb}$ hydrides the difference in binding energy is almost $10 \mathrm{eV}$, making it possible to separate the two components of the final state in the spectra. A comparison of experimental intensities of the $4 \mathrm{f}^{13}$ and $4 \mathrm{f}^{14}$ final states with model calculations allows the extraction of the parameters of the modified Anderson hamiltonian, in particular the $4 \mathrm{f}$ binding energy and the hybridisation strength. With these parameters one can calculate the ground state $\mid g>$ and thus the $4 \mathrm{f}$ occupancy.

The relative intensities of the different $4 \mathrm{f}^{\mathrm{n}}$ final states contributions in the photoemission spectra are a direct measure of the $4 \mathrm{f}$ occupancy in the ground state as Gunnarsson and Schönhammer /3/ have shown in the case of $\mathrm{Ce}$, and Monnier et al. /6/ in the case of $\mathrm{Yb} / 12 /$. In $\mathrm{Yb}$ the missing of a final state contribution implies the missing of the corresponding ground state. Therefore $3 \mathrm{~d}$ photoemission is a strong tool for determining the $\mathrm{Yb}$ valency.

\section{Experimental}

The XPS spectra were taken in a VG Escalab 5 spectrometer at a base pressure $1 \cdot 10^{-10}$ mbar. Si $\mathrm{K} \alpha$ radiation was used and the overall resolution was $1.6 \mathrm{eV} \mathrm{FWHM}$ 
of the $\mathrm{Au} 4 \mathrm{f}_{7 / 2}$ peak at $84.0 \mathrm{eV} . \mathrm{K} \alpha_{3,4}$ satellites were numerically corrected in the spectra. The nonmetallic $\mathrm{YbH}_{2.0}$ showed a shift in binding energy due to charging effects. The energies were calibrated with a gold wire on the surface of the hydride.

Yb metal (99.9\%, Research Chemicals) was cleaned in the preparation chamber of the spectrometer by repetitive $\mathrm{Ar}^{+}$bombardement, filing and outgassing at $400^{\circ} \mathrm{C}$ at $\mathrm{p} \approx 10^{-9}$ mbar. Hydrogenation was performed in a specially designed high pressure cell inside the spectrometer. The hydriding conditions are summarized in Table 1. Hydrogen was first cleaned by a $\mathrm{LN}_{2}$ cooled trap and a getter station down to about $1 \mathrm{ppm}$ contamination level.

Table 1:

\begin{tabular}{|c|c|c|c|}
\hline Hydride & $\begin{array}{l}\text { pressure } \\
\text { (bar) }\end{array}$ & $\begin{array}{l}\text { temperature } \\
\left({ }^{\circ} \mathrm{C}\right)\end{array}$ & $\begin{array}{l}\text { exposure time } \\
\text { (hours) }\end{array}$ \\
\hline $\mathrm{YbH}_{1.8}$ & $50-->1$ & 400 & 6 \\
\hline $\mathrm{YbH}_{2.0}$ & 50 & $40010^{\circ} \mathrm{C} / \mathrm{h} / 375$ & 6 \\
\hline $\mathrm{YbH}_{2.2}$ & 50 & $40010^{\circ} \mathrm{C} / \mathrm{h} / 350$ & 8 \\
\hline $\mathrm{YbH}_{2,6}$ & 50 & $40025^{\circ} \mathrm{C} / \mathrm{h}>250$ & 10 \\
\hline $\mathrm{YbD}_{2,6}$ & 50 & $40025^{\circ} \mathrm{C} / \mathrm{h} / 250$ & $24+4$ \\
\hline
\end{tabular}

Hydriding conditions of several hydrides. In $\mathrm{YbH}_{1.8}$ the pressure was 50 bars during 30 minutes. The hydrides were prepared in a high pressure cell inside the spectrometer, the deuteride in a separate reaction cell.

The samples were of cylindrical shape with about $1 \mathrm{~cm}$ of diameter. The hydride samples were of dark grey colour and brittle, but did not disintegrate into powder. To reduce oxygen diffusion to the surface the samples were cooled with liquid nitrogen to $\approx$ $100 \mathrm{~K}$ in the analyzing position. The hydrides were cleaned with a diamond file in situ immediately before taking the spectra. The contamination as determined from $\mathrm{O} 1 \mathrm{~s}, \mathrm{C} 1 \mathrm{~s}$, and $\mathrm{Yb} 4 \mathrm{p}$ peaks measured with $\mathrm{MgK} \alpha$ radiation was below $2 \%$. Structure, composition and homogeneity of the samples were checked after photoemission measurements by $\mathrm{X}$ ray diffraction and volumetric determination of the hydrogen liberated upon dissolution of parts of the samples in dilute acid.

The deuteride was prepared in two steps. After a first deuteration of the $\mathrm{Yb}$ metal, it was pulverized in an argon atmosphere and deuterated again. The powder was then filled in a copper coated vanadium vessel. Neutron measurements were performed at the multidetector powder diffractometer DMC at SAPHIR. The wavelength was $1.708 \AA$. 


\section{$\underline{\text { Results }}$}

Fig. 1 shows the $\mathrm{Yb} 3 \mathrm{~d}_{5 / 2}$ XPS spectra of $\mathrm{Yb}$ metal, several $\mathrm{Yb}$ hydrides and $\mathrm{Yb}+100 \mathrm{~L} \mathrm{O} 2\left(1 \mathrm{~L}=1 \mathrm{~s}\right.$ at $10^{-6}$ Torr $)$. The hydride spectra are characterized by two main features. The first is at about $1522 \mathrm{eV}$ binding energy and corresponds to a $\left|4 \mathrm{f}^{14} 3 \mathrm{~d}^{9} \mathrm{val}^{2}\right\rangle$ final state $\left(4 \mathrm{f}^{14}\right)$. It is a single line and is broadened only by lifetime and instrumental effects. The second is centered around $1530 \mathrm{eV}$ and corresponds mainly to a $14 \mathrm{f}^{13} 3 \mathrm{~d}^{9} \mathrm{val}^{3}>$ final state $\left(4 \mathrm{f}^{13}\right)$. The $3 \mathrm{~d}$ and $4 \mathrm{f}$ holes produce a multiplet structure, which significantly broadens this contribution. This multiplet is most clearly seen as the strong peak in the $\mathrm{Yb}+100 \mathrm{~L} \mathrm{O}_{2}$ spectrum, which is included in the figure as a reference . $\mathrm{Yb}_{2} \mathrm{O}_{3}$ is known to be trivalent having $4 \mathrm{f}^{13}$ configuration. The small $4 \mathrm{f}^{14}$ final state signal is due to remaining divalent $\mathrm{Yb}$, resulting from poor oxidation kinetics at room temperatures.

The most interesting and clearest result is the increase of the weight of the $4 \mathrm{f}^{13}$ peak from about zero in the dihydrides to about $50 \%$ in $\mathrm{YbH}_{2.6}$. The intermediate compound $\mathrm{YbH}_{2.2}$, which is a two phase mixture of $\mathrm{YbH}_{2}$ and $\mathrm{YbH}_{2.5}$, shows some scatter of the $4 \mathrm{f}^{13}$ final state relative intensity around a mean value of $30 \%$.

The spectra of the two dihydrides, $\mathrm{YbH}_{1.8}$ and $\mathrm{YbH}_{2.0}$, are dominated by the $4 \mathrm{f}^{14}$ final state. In the region of the $4 \mathrm{f}^{13}$ final state there is a very broad peak of low intensity. The center of this feature is at significantly higher binding energy than that of the $4 \mathrm{f}^{13}$ final state, suggesting a very low $4 \mathrm{f}^{13}$ final state intensity. This broad peak may be caused by band transition losses of the $4 \mathrm{f}^{14}$ final state. The backscattering electron energy loss spectra (EELS) of the dihydrides show broad losses starting $4.5 \mathrm{eV}$ below the elastic line, with a maximum at $14 \mathrm{eV}$.

The divalent $\mathrm{Yb}$ metal exhibits a pronounced $4 \mathrm{f}^{14}$ final state peak. Between 1525 and $1535 \mathrm{eV}$ electron losses from the $4 \mathrm{f}^{14}$ final state dominate the spectrum. A bulk and a surface plasmon $5.4 \mathrm{eV}$ and $9.4 \mathrm{eV}$, respectively, below the $4 \mathrm{f}^{14}$ line, overlap with a broad peak caused by band transition losses. Again these losses have been seen in recent EELS experiments /13/.

The experimental results clearly show a valence transition from divalent $\mathrm{YbH}_{2}$ with $4 \mathrm{f}^{14}$ configuration to mixed valent $\mathrm{YbH}_{2.6}$ with $4 \mathrm{f}^{13} / 4 \mathrm{f}^{14}$ configuration. Our calculations of the $3 \mathrm{~d}$ core level spectrum of $\mathrm{YbH}_{2.6}$ based on the Gunnarsson-Schönhammer formulation of the degenerate Anderson impurity model agrees qualitatively and quantitatively very well with a $50 \% 4 \mathrm{f}^{13} / 4 \mathrm{f}^{14}$ mixed valent configuration $/ 11 /$.

Magnetic properties, specially the absence of magnetic ordering at low temperature and the reported cubic symmetry of $\mathrm{YbH}_{2.6}$ indicate homogeneous mixed valence. 


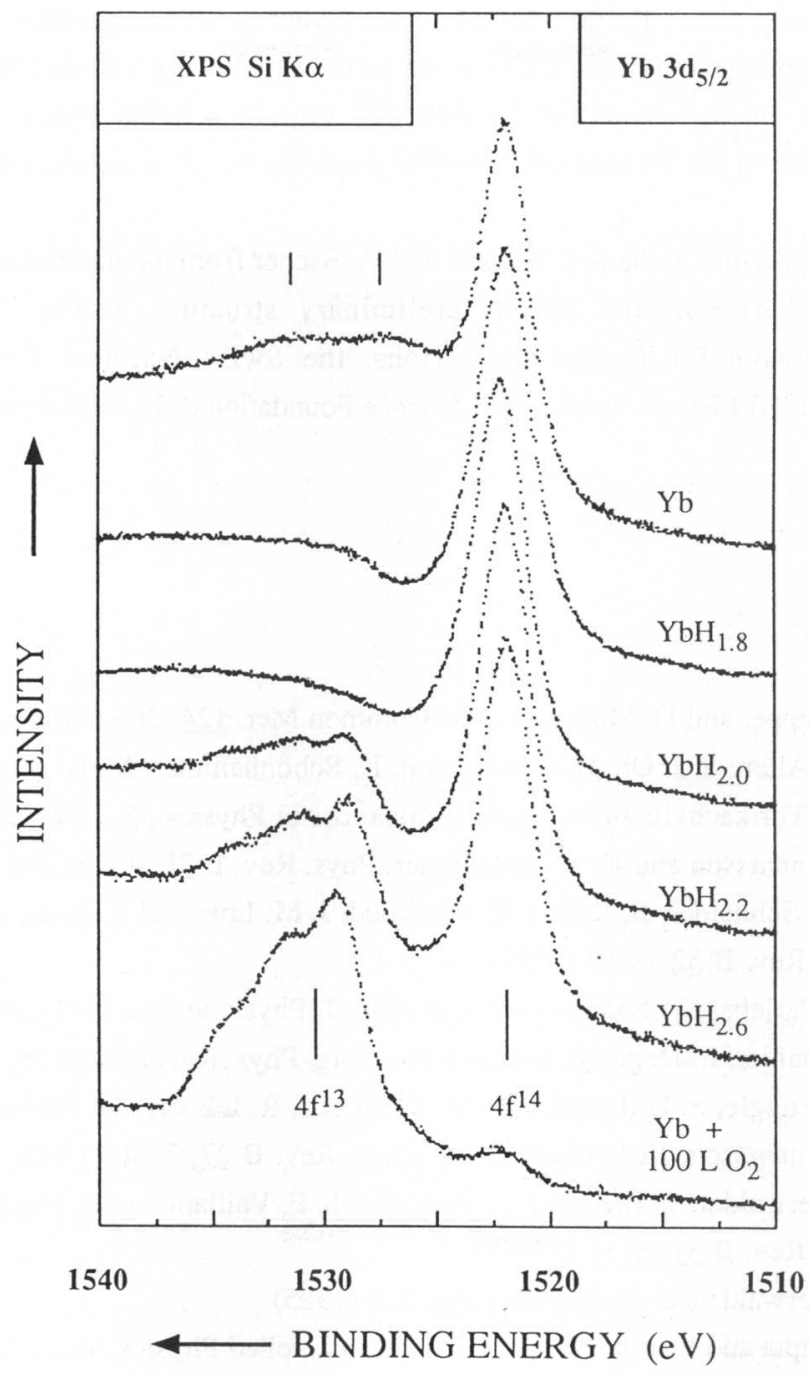

fig. 1: $\mathrm{Yb} 3 d_{5 / 2}$ core level spectra of $\mathrm{Yb}$ metal, $\mathrm{Yb}$ hydrides and $\mathrm{Yb}+100 \mathrm{LO} \mathrm{O}_{2}$. A clear transition from divalent $\mathrm{YbII}_{2}\left(4 f^{14}\right)$ to mixed valent $\mathrm{YbH}_{2.6}\left(4 f^{13} / 4 f^{I 4}\right)$ occurs. Si $\mathrm{K} \alpha_{3,4}$ salellite structures have been numerically subtracted. $4 f^{n}$ indicates $a 4^{n} 3 d^{9}$ val ${ }^{3}$ final state configuration. In the $Y b$ spectrum a bulk and a surface plasmon are indicated. 
In order to clarify the question of homogeneous or inhomogeneous mixed valence a structure refinement of neutron diffraction patterns of $\mathrm{YbD}_{2.6}$ was started. Some peaks in addition to the pattern of the fcc structure suggest a larger unit cell due to small displacements of the $\mathrm{Yb}$ ions and a possible smearing out of some octahedral D sites /14/.

It is a pleasure to thank J. Schefer and P. Fischer from the neutron diffraction group at Paul Scherrer Institut for the preliminary structure results, T. Greber and H. C. Siegmann for fruitful discussions, the Swiss National Energy Research Foundation (NEFF) and the National Science Foundation (NF) for financial support.

\section{References}

1 P. Knappe, and H. Müller, J. Less-Common Met. 124, 263 (1986)

2 J. W. Allen, S. J. Oh, O. Gunnarsson, K. Schönhammer, M. B. Maple, M. S. Torikachvili and I. Lindau, Advances in Physics 35, 275 (1986)

3 O. Gunnarsson and K. Schönhammer, Phys. Rev. B 28, 4315 (1983)

4 W. D. Schneider, B. Delley, E. Wuilloud, J. M. Imer and Y. Baer, Phys. Rev. B 32, 6819 (1985)

5 J. C. Parlebas, T. Nakano and A. Kotani, J. Physique 48 , 1141 (1987)

6 R. Monnier, L. Degiorgi and D.D. Koelling, Phys. Rev. Letters $\underline{56}, 2744$ (1986)

7 J. C. Fuggle, F. U. Hillebrecht, Z. Zolnierek, R. Lässer, Ch. Freiburg, O. Gunnarsson, K. Schönhammer, Phys. Rev. B 27. 7330 (1983)

8 J. Osterwalder, T. Riesterer, L. Schlapbach, F. Vaillant and D. Fruchart, Phys. Rev. B 31, 8311 (1985)

9 J. Osterwalder, Z. für Physik B 61, 113 (1985)

10 M. Gupta and L. Schlapbach, in Topics in Applied Physics, Vol. 63, L. Schlapbach, ed., Springer Heidelberg (1988), p. 139

11 St. Büchler, L. Schlapbach, R. Monnier, L.Degiorgi, J. Physique 12, C9 - 947 (1987)

12 see also fig.7 , p. 4322 of Ref. 3

13 A. Stenborg, E. Bauer, Surface Science 66, 561 (1988)

14 J. Schefer et al., to be published 